\title{
Granulocyte-Macrophage Colony Forming Unit
}

National Cancer Institute

\section{Source}

National Cancer Institute. Granulocyte-Macrophage Colony Forming Unit. NCI

Thesaurus. Code C121475.

A unit of viable cell concentration defined as the minimum number of hematopoietic stem cells able to produce a detectable colony of granulocyte-macrophage lineage cells. 